\title{
Low-cost Processing Technology for the Synthesis of Calcium Phosphates/Collagen Biocomposites for Potential Bone Tissue Engineering Applications
}

\author{
Maria Helena Santos ${ }^{\mathrm{a}}$, Herman Sander Mansur ${ }^{\mathrm{b} *}$ \\ ${ }^{a}$ Department of Dentistry, Federal University of Vales do Jequitinhonha e Mucuri - ICS/UFVJM, \\ Rua da Glória, 187, 39100-000 Diamantina - MG, Brazil \\ ${ }^{\mathrm{b}}$ Department of Metallurgical and Materials Engineering, \\ Federal University of Minas Gerais - EE/UFMG, \\ Rua Espírito Santo, 35/316, 30160-030 Belo Horizonte - MG, Brazil
}

Received: May 20, 2007; Revised: December 3, 2007

\begin{abstract}
In the present study two novel composites of Calcium phosphates $(\mathrm{CaP})$ and Collagen $(\mathrm{COL})$ were synthesized, hydroxyapatite/Collagen (HA/COL) and hydroxyapatite- $\beta$ tricalcium phosphate/COL (HAßTCP/COL). Collagen was extracted from bovine pericardium submitted to enzymatic digestion and purification by ion-exchange chromatography yielding high purity grade type I collagen. Biocomposites of HAP/COL and HA $\beta T C P / C O L$ were produced with a calcium phosphate/COL ratio of 80/20 (wt. (\%)) and were characterized by chemical analysis, light microscopy and scanning electron microscopy, $\mathrm{X}$ ray diffraction and FT-infrared spectroscopy. SEM results of the $\mathrm{CaP}$ powders showed agglomerates of particles at the nanometric size range with predominantly columnar shape and average chemical composition of $[\mathrm{Ca} / \mathrm{P}]=1.67$. FTIR analysis of collagen has confirmed the major vibrational bands associated with chemical groups like amides and hydroxyls usually found in proteins. SEM micrographs have indicated that both morphological and structural features and chemical composition of the composites were very similar to their precursors, collagen and calcium phosphate components. SDS-PAGE characterization results of protein extracted and purified has showed that bovine type I collagen was successfully obtained. Finally, the biocomposites presented a homogeneous aspect with the calcium phosphate particles aggregated to the collagen fibers. Hence, the novel developed biocomposites have high potential to be used for rebuilding small lesions in bone tissue engineering.
\end{abstract}

\section{Keywords: biomaterials, hydroxyapatite, collagen, biocomposites}

\section{Introduction}

The regeneration and or substitution of damaged parts of the body, including bones, has been a longtime concern for the health professional. Materials from various sources have been tried but yet few have showed satisfactory results.

The potential use of properly designed synthetic biomaterials in the regeneration of hard tissues is significant because they usually do not cause damages in healthy tissues, have a low risk of bacterial contamination, and can also be readily and commercially available ${ }^{1}$. However, despite of biomaterials have been extensively investigated some concerns regarding to the biocompatibility behavior are yet to be fully understood. For instance, synthetic or natural biomaterials may induce minor inflammatory and immunological responses on the host depending on specificity of each living organism. Another goal to be pursuit under developing new biomaterials is the widest availability of them to the population, which is associated with inexpensive manufacturing in large scale.

The Calcium phosphates $(\mathrm{CaP})$ belong to the group of bioactive synthetic materials and its most frequently used representative are the hydroxyapatite, $\mathrm{Ca}_{10}\left(\mathrm{PO}_{4}\right)_{6}(\mathrm{OH})_{2}$, and the hydroxyapatite- $\beta$ tricalcium phosphate, $\mathrm{Ca}_{3}\left(\mathrm{PO}_{4}\right)_{2}$, due to their osteoconductivity, crystallographic structures and chemical composition similar to the skeletal tissue ${ }^{2}$. The association of hydroxyapatite and hydroxyapatite- $\beta$ tricalcium determines the biocompatibility and biodegradability properties to suit the need of different applications of these materials in several parts of the organism. Henceforth those materials are more and more applied in medical, pharmacological and dentistry areas ${ }^{3,4}$.
Among the natural polymers, the collagen is the protein more frequently used as a biomaterial ${ }^{5-7}$. The type I collagen, the most common type of collagen, constitutes the major component of the osseous tissue ${ }^{6}$. The intense use of this biopolymer in the biological area is due to its natural properties such as high biocompatibility and biodegradability, low toxicity and immunogenicity compared to other natural polymers. Its structure and interaction with the tissue make it an efficient matrix to produce diverse forms of biomaterials and to use it as a scaffold in tissue engineering ${ }^{8}$.

Bovine pericardium has been widely used as raw material for biomaterials possessing the collagen as the fundamental structural molecule ${ }^{9,10}$. The bovine collagen is a biological heterologous material with adequate biophysical properties ${ }^{10}$ that can be handled and obtained easily and has a low cost because is considered a byproduct of the animal in the slaughterhouse.

Biodegradable polymers and bioactive ceramics are combined in a great variety to form composite materials to be used in the substitution and regeneration of the osseous tissue ${ }^{8,10}$. The $\mathrm{CaP} /$ collagen composites have been developed as potential biomaterials for the bone substitution ${ }^{7,11-12}$. Important aspects of the use of collagen in the form of composites with bioceramics is the fact that this protein is the matrix where the calcium phosphate salts are deposited to give origin to the osseous tissue ${ }^{13}$ with improved mechanical properties such as elastic modulus and toughness closer to that of the bone $\mathrm{e}^{5,14,15}$. Hence, by combining protein with calcium phosphates one aims to get the best of both worlds, that means, composites based on organic joined 
to inorganic reaching the designed properties. The interest in this area owes to the increasing clinical applications of the $\mathrm{CaP} /$ collagen biocomposites and the main studies are oriented for the improvement of its physiochemical properties and its processing that still exhibit shortcomings ${ }^{16-20}$.

The production of biocomposites through economically feasible processes remains a matter of great concern. Commonly, expensive processes are used for this end turning these materials economically nonviable. The development of composites for regeneration of the osseous tissue pondering the cost and availability of the raw materials and the process simplicity is of ultimate importance to fulfill the increasing demand for such materials in the various areas of health.

The objective of this work was to synthesize calcium phosphates, to extract and to purify the collagen type I of tissular origin of the bovine pericardium and to develop novel calcium phosphates/collagen biocomposites for bone tissue engineering through direct procedures, using regular reagents and equipment commercially available.

\section{Experimental Procedure}

\subsection{Materials preparation and synthesis}

The calcium phosphates $(\mathrm{CaP})$ were synthesized by wet precipitation route based on stoichiometric molar ratio for pure hydroxyapatite, $\mathrm{Ca} / \mathrm{P}=1.67$, in accordance with the proposed reaction (Equation 1 ), as previously reported in our work $\mathrm{k}^{21}$ :

$$
\begin{aligned}
& 10 \mathrm{Ca}(\mathrm{OH})_{2 \text { (susp) }}+6 \mathrm{H}_{3} \mathrm{PO}_{4(\text { aq) }} \\
& \mathrm{Ca}_{10}\left(\mathrm{PO}_{4}\right)_{6}(\mathrm{OH})_{2}+18 \mathrm{H}_{2} \mathrm{O} \downarrow
\end{aligned}
$$

To synthesize $10 \mathrm{~g}$ of calcium phosphate a $40 \mathrm{mM} \mathrm{Ca}(\mathrm{OH})$, suspension was used. Initially, the $\mathrm{Ca}(\mathrm{OH})_{2}$ powder was added slowly into deionized water at $40 \pm 3{ }^{\circ} \mathrm{C}$ temperature and vigorously agitated for one hour. To this solution a $17 \mathrm{mM} \mathrm{H}_{3} \mathrm{PO}_{4}$ solution was added dropwise with ratio of $6 \mathrm{~mL} / \mathrm{min}$ approximately. The $40 \pm 3{ }^{\circ} \mathrm{C}$ temperature, vigorous and constant agitation was maintained throughout the process. The $\mathrm{pH}$ was controlled to a minimum of $7.0 \pm 1.0$ during the addition of acid to the $\mathrm{Ca}(\mathrm{OH})_{2}$, suspension using a $1.0 \mathrm{M} \mathrm{NH}_{4} \mathrm{OH}$ solution. After the complete mixture of the two reagents, $\mathrm{H}_{3} \mathrm{PO}_{4}$ (conc.) was added under vigorous agitation for more 30 minutes. The solution rested at room temperature for 24 hours. After decantation, the precipitate was subjected to vacuum filtering and washed for three consecutive times with deionized water at room temperature. The precipitates were dried at $100{ }^{\circ} \mathrm{C}$ temperature for 12 hours. Then, the synthesized powder was crushed and passed through sieve set of 200 and 400 mesh. Some samples were submitted to the thermal treatment with a heating rate of $10{ }^{\circ} \mathrm{C}$ per minute and maintained at $900{ }^{\circ} \mathrm{C}$ for two hours and other samples were submitted at $1100{ }^{\circ} \mathrm{C}$ temperature in the same conditions. All samples were submitted to fast cooling after thermal treatment.

Bovine pericardium (BP) was obtained from animals with approximately 18-24 months of age. The fatty tissue surrounding the pericardium was thoroughly removed and the tissue was dissected, cut into pieces (approx. $1 \times 1 \mathrm{~cm}$ ) and treated with a $0.1 \mathrm{M} \mathrm{NaOH}$ solution for 48 hours at $4{ }^{\circ} \mathrm{C}$. The material was washed, homogenized into a paste (Ultra-Turrack T25 - Jankel \& Kunkel) and digested with pepsin (800-2500 U.mg ${ }^{-1}$ - Sigma, St Louis, USA) dissolved in $10 \mathrm{mM} \mathrm{HCl}$ at $\mathrm{pH} 2.0$ for approximately 20 hours. The proportion of pepsin to bovine pericardium was 1:20 (wt.wt $\left.{ }^{-1}\right)$. The mixture was centrifuged for $20 \mathrm{~min}$ at $10,000 \mathrm{~g}$ at $4{ }^{\circ} \mathrm{C}$ and the supernatant was removed. Urea $(2 \mathrm{M})$ and $50 \mathrm{mM} \mathrm{NaCl}$ was added to the supernatant and the $\mathrm{pH}$ was adjusted to 7.0 with $1 \mathrm{M}$ Tris. This supernatant was named crude collagen and it was collected as aliquot and then stored at $-20{ }^{\circ} \mathrm{C}$ until use. The diethylaminoethyl (DEAE)-sepharose CL-6B resin (Amersham Biosciences, Uppsala, Sweden) was packed into a column and equilibrated with $40 \mathrm{mM}$ Tris- $\mathrm{HCl}$ buffer containing $2 \mathrm{M}$ urea and $50 \mathrm{mM} \mathrm{NaCl}$. The column was connected to the low pressure liquid chromatography system (Pharmacia). The crude collagen sample was applied to the column and unbound material eluted with $1 \mathrm{X}$ column volume of equilibrium buffer (flow rate $=2.0 \mathrm{~mL} / \mathrm{min}$; washing phase $=500 \mathrm{~mL}$ of buffer solution Tris- $\mathrm{HCl} 40 \mathrm{mM}$ ). Type I collagen was subsequently eluted with $0.10 \mathrm{M} \mathrm{NaCl}$ in the buffer at $3 \mathrm{~mL} / \mathrm{min}$. After elution the protein (COL) was dialyzed against $0.001 \mathrm{M}$ PBS solution for 16 hours at $4{ }^{\circ} \mathrm{C}$ temperature. Finally, COL was frozen at $-80{ }^{\circ} \mathrm{C}$ and lyophilized ${ }^{22}$.

The $\mathrm{CaP}$ materials were produced with $\mathrm{COL}$ using the $\mathrm{CaP} / \mathrm{COL}$ ratio of 80/20 (wt. (\%)). The composite was prepared adding HAP powder in $\mathrm{COL}$ diluted in $0.1 \mathrm{~N} \mathrm{CH}_{3} \mathrm{COOH}$ (weak acid, $\mathrm{pK}_{\mathrm{a}}=4.8$, low conc., low dissolution of HAP powder) solution at a concentration of $0.5 \mathrm{mg} \cdot \mathrm{mL}^{-1}$. The mixture was maintained under slow agitation at $37 \pm 3{ }^{\circ} \mathrm{C}$. After 12 hours, the mixture was lyophilized and stored at $4{ }^{\circ} \mathrm{C}$.

\subsection{Characterization}

The $\mathrm{CaP}$ powders were dispersed in $\mathrm{H}_{2} \mathrm{O}$ /ethanol solution and dried on a glass slide at $40{ }^{\circ} \mathrm{C}$. Samples of $\mathrm{CaP}, \mathrm{COL}$ and $\mathrm{CaP} / \mathrm{COL}$ were sputtered with an ultra thin layer of gold. The morphology and the semi-quantitative elementary analysis of the samples microareas were obtained by energy dispersive $\mathrm{X}$ ray spectroscopy (EDS) and Scanning Electron Microscopy (SEM) (JSM model 6360LV - JEOL, Japan) at an accelerating voltage of 10 to $15 \mathrm{keV}$. The Ca and P concentrations and the quantitative analysis of other chemical elements were also determined as well as the molar ratio of the $\mathrm{Ca} / \mathrm{P}$ synthesized powders. The results were determined from the chemical analysis of three different areas of the materials for each sample.

The COL was characterized by SDS-PAGE and compared with the commercial bovine type I collagen (Sigma, St Louis, USA).

The phase identification and phase purity of the materials were measured by X ray diffraction (XRD) (PW 1710 - Philips, Netherlands) with monochromatized $\mathrm{CuK}_{\alpha}$ radiation and operational tube with voltage and current of $40 \mathrm{kV}$ and $30 \mathrm{~mA}$ respectively. The equation ${ }^{23} \operatorname{sen}^{2} \theta=\lambda^{2} / 4\left[4 / 3\left(\mathrm{~h}^{2}+\mathrm{hk}+\mathrm{k}^{2}\right) / \mathrm{a}^{2}+\mathrm{l}^{2} / \mathrm{c}^{2}\right]$, where $\lambda^{2} / 4$ have the value of $0.594 \AA$ and $1.5418 \AA \mathrm{CuK}_{\alpha}$ radiation, was used to determine the structural parameters of $\mathrm{CaP}$ samples along (211) and (112) directions.

The chemical characteristics of functional groups of the samples were analyzed by Fourier-Transformed Infrared Spectroscopy (FTIR, Perkin-Elmer, Paragon 1000), which were obtained by using diffuse reflectance mode (DRIFTS). CaP powder, lyophilized COL and $\mathrm{CaP} / \mathrm{COL}$ samples were dispersed with pre-dried $\mathrm{KBr}\left(110{ }^{\circ} \mathrm{C}\right.$, 2 hours, spectroscopy grade, Sigma) with a weight ratio of 1:10 for measurements. The resolution was $4 \mathrm{~cm}^{-1}$ and interations were performed for 256 times in the range from $450-4000 \mathrm{~cm}^{-1}$. Background noise was corrected with pure $\mathrm{KBr}$ data.

\section{Results and Discussion}

SEM analysis of the CaP powders showed an aggregate and granular material with nanometric particles of columnar shape (Figure 1). The EDS spectrum showed a superior concentration of $\mathrm{P}$ and $\mathrm{Ca}$ elements and smaller concentrations of other elements. The aspect of the synthesized powders showed the typical apatite-like morphology and the nanometric particles of the precipitate presented columnar shape commonly reported for these materials ${ }^{24,25}$. As expected, the major element components were $\mathrm{P}$ and $\mathrm{Ca}$ and other trace elements were detected as $\mathrm{Na}, \mathrm{Mg}, \mathrm{Si}, \mathrm{Sr}, \mathrm{S}$ and $\mathrm{Cl}$. 


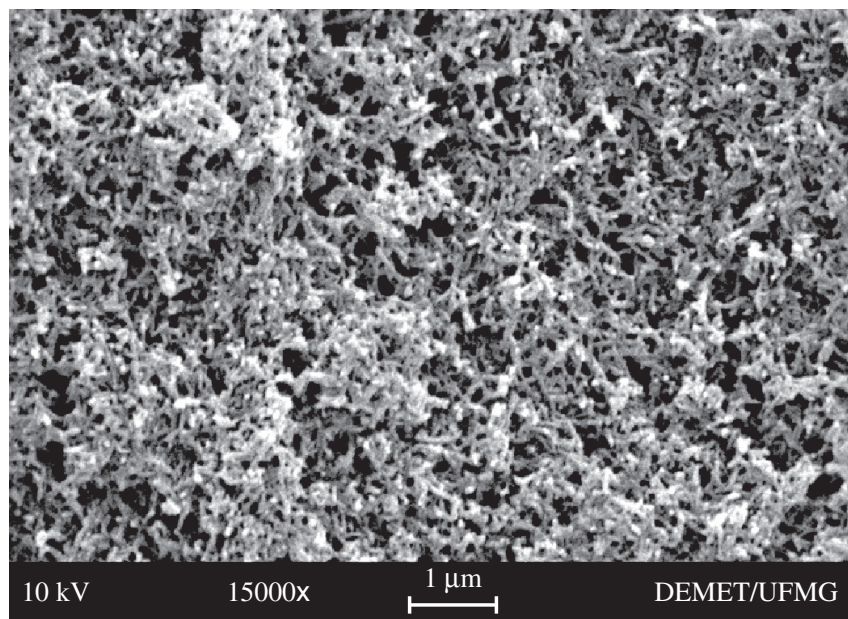

Figure 1. SEM photomicrograph of the precipitated HAP particles.

The type I collagen has the triple-helix conformation and this secondary helical structure is composed of $2 \times \alpha 1$ and $1 \times \alpha 2$ that is produced by the strong hydrogen bond and the amide $\mathrm{A}$ of collagen matrix ${ }^{5}$. The localization of the $2 \alpha 1$ and $\alpha 2$ bands of the COL in the polyacrylamide gel (Figure 2a) was showed close to type I collagen described in the literature and also to the commercial collagen (Sigma, Collagen Type-I ) used as purity control (Lane 1, Figure 2b). Several molecular weight markers (Sigma, USA, Table 1) were used in order to properly characterize the extraction of collagen type-I from bovine pericardia and further purification procedure. Briefly, $3 \mu \mathrm{L}$ of each protein standard (Table 1) was used and from 10 a $30 \mu \mathrm{L}$ of collagen samples to be analyzed were submitted to the assay. The ion exchange chromatography performed well eluting COL under the condition used ${ }^{18,22}$

The COL photomicrographs (Figure 3) showed an amorphous structure with disordered fibrils and areas with irregular and scattered pores. It is worth to point out that their connectivity may play an important role on new bone-growth and needs to be properly investigated by some technique like Micro-CT analysis. The morphologic and structural characteristics and the qualitative chemical composition of the composites showed similar characteristics to their constituent materials. SEM micrographs of the CaP/COL composites (Figure 4a) showed a homogeneous aspect with the calcium phosphate particles aggregated to the collagen fibers. The EDS spectrum showed peaks of high intensity corresponding to the presence of high amount of carbon (C), and peaks of low intensity corresponding to the trace elements $\mathrm{Cl}$ and $\mathrm{Na}$ of the $\mathrm{COL}$ processing and peaks corresponding to the $\mathrm{CaP}$ constitution (Figure $4 \mathrm{~b}$ ).

Table 2 presents the structural characteristics of synthesized HAP. Chemical analysis revealed a $\mathrm{Ca} / \mathrm{P}$ molar ratio of 1.64 , compatible with calcium-deficient hydroxyapatites ${ }^{2,26}$. The results of the quantitative analysis of elements showed $\mathrm{Ca}$ and $\mathrm{P}$ concentrations around 38 and $16 \%$ respectively. The concentration of other trace elements were observed varying from 0.001 to $0.2(\%)$. These elements were the same found in the elementary analysis by EDS.

The dimensions of the cell unit of the HAP crystals were calculated based in the values obtained of the typical XRD pattern considering that the cell unit of the hydroxyapatite belongs to the hexagonal crystals system characterized by two variable parameters, a and $\mathrm{c}^{23}$. X ray diffraction analysis confirmed that HAP displayed the characteristic profile of pure hydroxyapatite with unit cell parameters $\mathrm{a}=\mathrm{b}$ and $\mathrm{c}$ of 9.449 and 6.980 respectively. The XRD results of the synthesized materials are showed in Figure 5. After thermal treatment, the samples showed the X-ray diffraction patterns of the $\mathrm{CaP}$ synthe-
Table 1. Structural parameters and chemical analysis of HAP synthesized.

\begin{tabular}{lccc}
\hline \multicolumn{1}{c}{ Sample } & \multicolumn{2}{c}{ Unit cell } & Molar ratio \\
& parameters $(\AA)$ & Ca/P \\
\cline { 2 - 3 } & $\mathrm{a}=\mathrm{b}$ & $\mathrm{c}$ & \\
\hline Pure hydroxyapatite(Reference) & 9.424 & 6.879 & 1.67 \\
Calcium-deficient hydroxyapatite & 9.420 & 6.880 & 1.64 \\
HAP & 9.449 & 6.980 & 1.64 \\
\hline
\end{tabular}

Table 2. Standard Molecular weight markers for collagen characterization.

\begin{tabular}{lc}
\hline \multicolumn{1}{c}{ Molecular weight $(\mathrm{Mw})$ standard markers } & $\mathrm{Mw}(\mathrm{kDa})$ \\
\hline Alpha-macroglobulin & 193.0 \\
IgG rabbit conjugate Anti-IgG sheep & 135.0 \\
Beta-galactosidase & 112.0 \\
Frutose-6-phosphate & 86.0 \\
Pyruvate quinase & 70.0 \\
Fumarase & 57.0 \\
Lactate dehydrogenase & 39.5 \\
Triose-phosphate isomerase & 36.0 \\
\hline
\end{tabular}

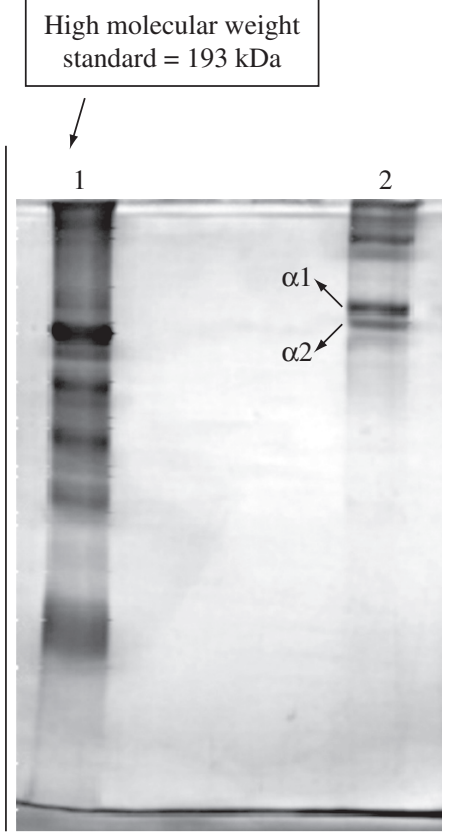

(a)

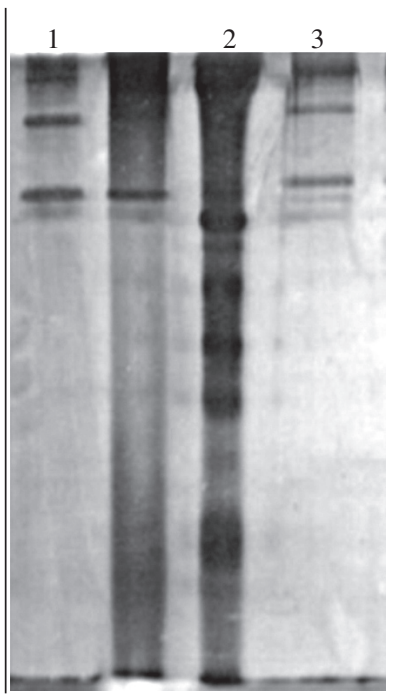

(b)
Figure 2. Electrophoresis in 12\% sodium dodecylsulfate-polyacrylamide (A) molecular weight standard (SDS, 7B - Sigma) (1), DEAE-sepharose purified collagen (COL) showing typical bands of the type I collagen; (B) commercial collagen (type I collagen - Sigma) used as purity control (1), molecular weight standard (Table 2) (2) and COL (3).

sized powders as reported in the literature ${ }^{2,21,25,26}$. The XRD patterns of the HAP $\beta$ TCP powder indicated the presence of two crystalline phases, hydroxyapatite (HAP) and a smaller amount of $\beta$-tricalcium phosphate ( $\beta$ TCP). The HAP crystals revealed characteristic peaks in the XRD pattern that were consistent with JCDS 2001 (Joint Committee on Powder Diffraction Standards, ICDD - International Center for Diffraction Data) files for hydroxyapatite and in agreement with synthesized hydroxyapatite published in the literature ${ }^{27,28}$. 


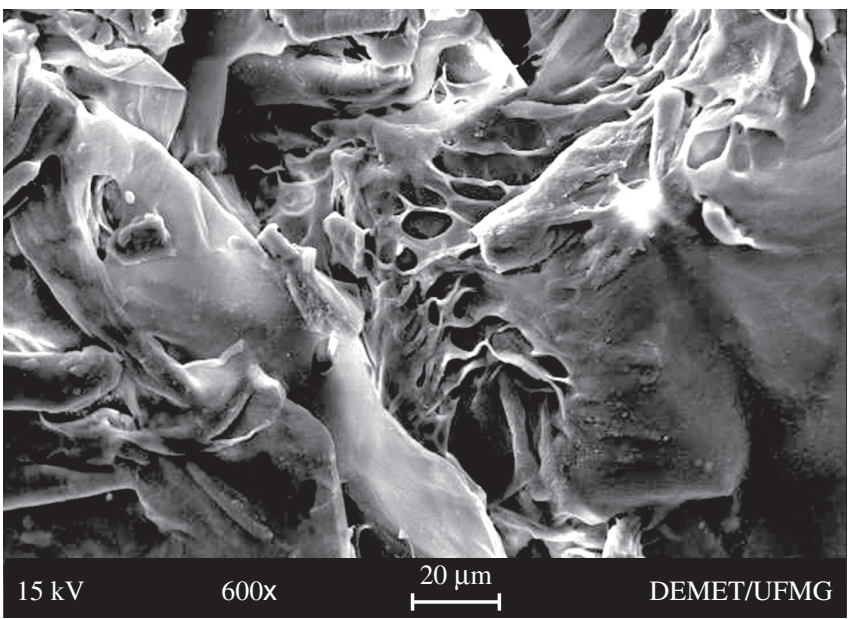

Figure 3. SEM photomicrograph of the amorphous structure of COL showing the presence of fibers and pores.

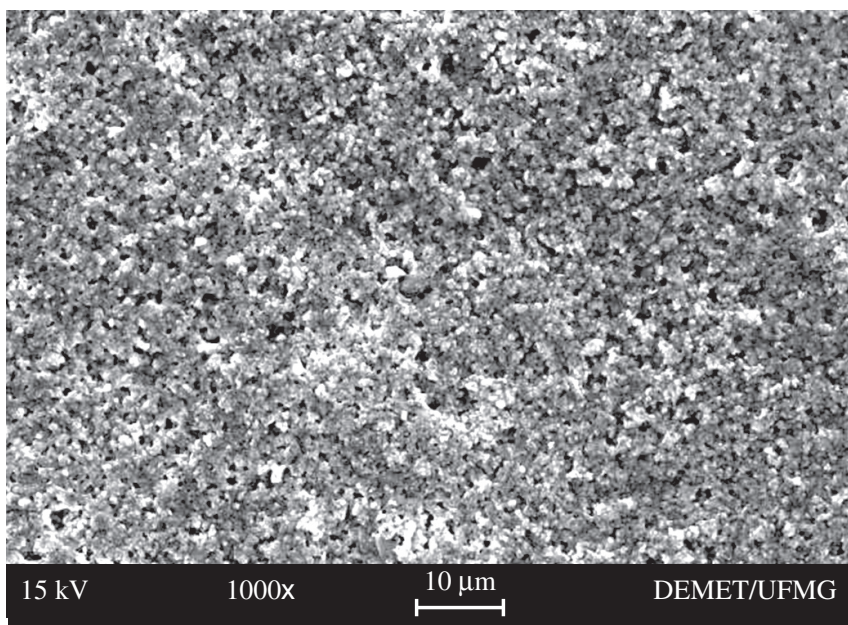

(a)

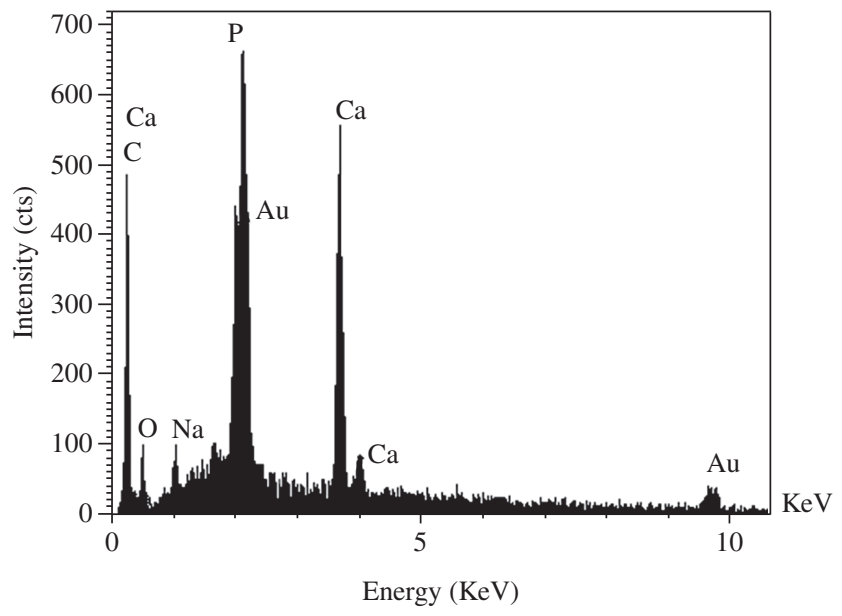

(b)

Figure 4. a) SEM photomicrograph of HAP particles aggregated to COL constituting the HAP/COL composite; and b) EDS spectra with elementary qualitative analysis of the composite showing a greater concentration of $\mathrm{P}$ and Ca elements and smaller concentrations of other elements.
The COL presented a characteristic XRD spectra showing an amorphous phase since it is an organic material. The CaP/COL composites presented defined peaks with less width in spite of the presence of an amorphous phase (Figure 5). This suggests the association of a crystalline material to an amorphous material ${ }^{27}$.

FTIR spectra of HAP/COL and HAP $\beta T C P / C O L$ composites were very similar to the spectra of natural bone and other hydroxyapatite/collagen systems ${ }^{29,30}$. HAP/COL composite showed the carbonate $v 2$ mode at $840 \mathrm{~cm}^{-1}$, the phosphate mode $v 1$, asymmetric mode of phosphate $\mathrm{v} 3$ as similar to the spectra of HAP and the amide $\mathrm{I}(\mathrm{C}=\mathrm{O}$, $\left.1653 \mathrm{~cm}^{-1}\right)$, amide II $\left(\mathrm{N}-\mathrm{H}, 1535 \mathrm{~cm}^{-1}\right)$ and amide III (C-N and $\mathrm{N}-\mathrm{H}$, $1244 \mathrm{~cm}^{-1}$ ) as similar to the spectra of COL (Figure 6). The amide band regions of the spectrum are directly related to the polypeptide conformation. Specially, the amide I band in a bone spectrum is representative of the collagen content and structure ${ }^{31}$. The appeareance of an amide I mode at $1653 \mathrm{~cm}^{-1}$ indicated that $\mathrm{CaP} / \mathrm{COL}$

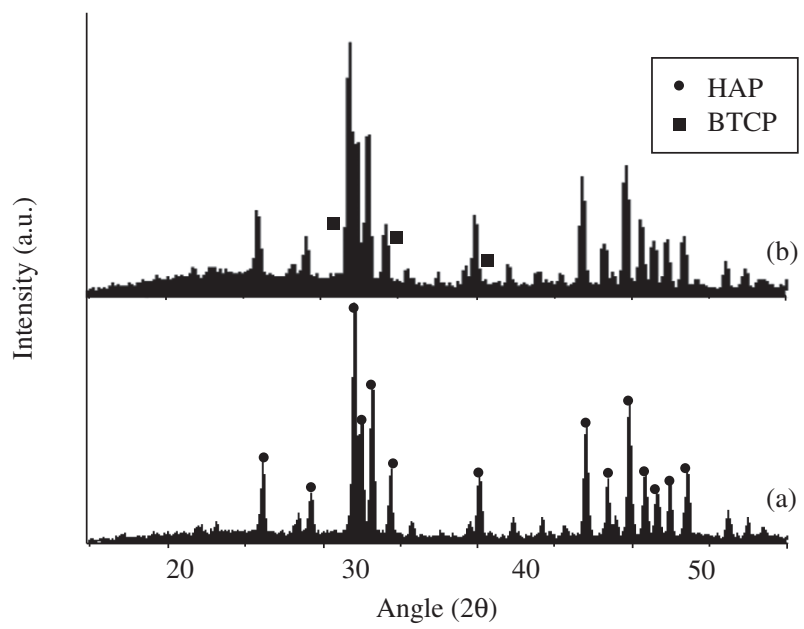

Figure 5. XRD spectrum of HAP/COL composite showing characteristic peaks of pure hydroxyapatite and the presence of amorphous material (a), XRD spectrum of HAP $\beta T C P / C O L$ showing the presence of two crystalline phases, hydroxyapatite (HAP) and a smaller amount of $\beta$-tricalcium phosphate ( $\beta$ TCP) (b).

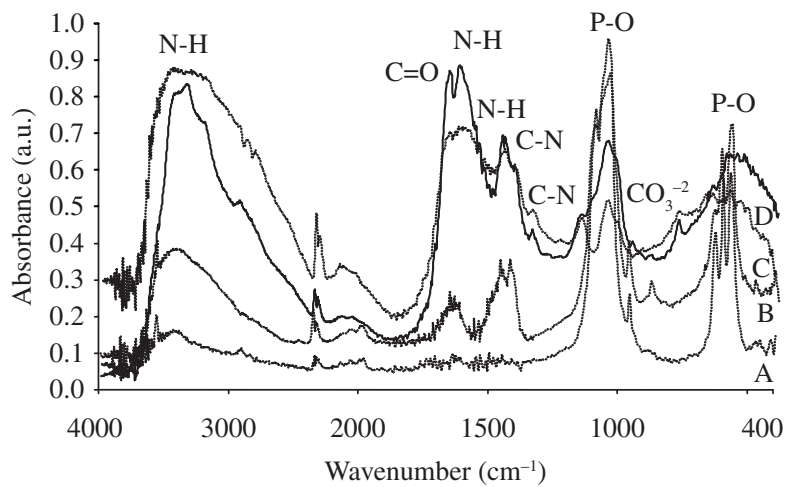

Figure 6. FTIR spectra of (A) HAP $\beta$ TCP and (B) HAP showing the presence of bands corresponding to groups $\mathrm{PO}_{4}^{3-}$ at 600 and $1100 \mathrm{~cm}^{-1}$, groups $\mathrm{OH}$ of $\mathrm{P}-\mathrm{OH}$ bond at $870 \mathrm{~cm}^{-1}$, groups $\mathrm{OH}$ of the structural and adsorbed $\mathrm{H}_{2} \mathrm{O}$ molecules at 3570 and $3400 \mathrm{~cm}^{-1}$ respectively; (C) COL showing the correspondent peaks of the amide A, amide I, amide II and amide III at 3449 and $3343,1653,1535,1244 \mathrm{~cm}^{-1}$ respectively and a typical protein region at $600-800 \mathrm{~cm}^{-1}$; (D) HAP/COL composite showing characteristic bands of HAP and COL chemical bonds. 
composites adopted a predominantly $\alpha$-helical configuration ${ }^{30}$ and this is confirmed by the appearance of amide-II mode at $1458 \mathrm{~cm}^{-1}$. The $\mathrm{CO}_{3}^{-2}$ band at $871 \mathrm{~cm}^{-1}$ indicated the formation of the $\beta$-type carbonate in the $\mathrm{HAP}^{31}$.

The utilization of an aqueous precipitation reaction for the preparation of different calcium phosphates makes it possible to obtain single phase hydroxyapatite (HAP), hydroxyapatite- $\beta$ tricalcium ( $\beta$ TCP) and also biphasic HAP $\beta$ TCP materials. BP constitutes an attractive alternative to synthetic fibers. It is a biological material with high collagen content of easy handling and low cost presenting excellent biocompatibility and intrinsic biological properties. The purified bovine type I collagen (COL) was obtained through anion exchange chromatography using a simple and conventional technique. The chemical treatment used in the COL preparation prevented the organization of the microfibrils of the collagen molecule. The COL showed similar morphology to commercial bovine type I collagen. The process of single mixture of $\mathrm{CaP}$ and COL provided stable composites with HAP nanocrystals aggregated along COL fibers by the chemical interaction between them. The obtained $\mathrm{CaP} / \mathrm{COL}$ composites had a similar nanostructure to bone.

\section{Conclusion}

Novel biocomposites based on calcium phosphates and purified type-I collagen were synthesized and extensively characterized through chemical, structural and morphological features. In addition, the precursor materials were obtained via low-cost processing methods, where the inorganic component was basically produced by calcium phosphates aqueous route and the organic phase type-I collagen from bovine pericardia tissue. In summary, this research has showed a new technology method of using widely available sources to produce biocomposites for potential use in several fields of medicine and dentistry such as in bone tissue engineering.

\section{Acknowledgments}

The authors acknowledge the financial support provided by CAPES and FAPEMIG. Also, they would like to express their gratitude to Dr. Luiz Guilherme D. Heneine from the Department of Health Science, Ezequiel Dias Foundation (FUNED), for his remarkable contribution on the collagen extraction and purification procedures.

\section{References}

1. Willians DF. Definitions in biomaterials. 4 ed. New York: Elsevier; 1987.

2. LeGeros, RZ. Properties of Osteoconductive Biomaterials: Calcium Phosphates. Clinical Orthopaedics and Related Research. 2002; 395:81-98.

3. Yang X, Wang Z. Synthesis of biphasic ceramics of hydroxyapatite and beta-tricalcium phosphate with controlled phase content and porosity. Journal of Materials Chemistry. 1998; 8:2233-2237.

4. Peña J, Vallet-Regi M. Hydroxyapatite, tricalcium phosphate and biphasic materials prepared by a liquid mix technique. Journal of the European Ceramic Society. 2003; 23(10):1687-1696.

5. Yannas IV. Natural Materials. In: Ratner BD, Hoffman AS, Schoen FJ, Lemons JE, editors. Biomaterials science: an introduction to materials in medicine. San Diego, California-USA: Academic Press. 1996; p. 84-94.

6. Santos MH, Valerio P, Goes AM, Leite MF, Heneine LGD, Mansur HS. Biocompatibility evaluation of hydroxyapatite/collagen nanocomposites doped with $\mathrm{Zn}^{+2}$. Biomed. Mater. 2007; 2(2):135-141.

7. Tirrel M, Kokkoli E, Biesalski M. The role of surface science in bioengineered materials. Surface Science. 2002; 500(1):61-83.

8. Rezwan Z, Chen QZ, Blaker JJ, Boccaccini AR. Biodegradable and bioactive porous polymer/inorganic composite scaffolds for bone tissue engineering. Biomaterials. 2006; 27(18):3413-3431.
9. Lee WK, Park KD, Han DK, Sush H, Park JC, Kim YH. Heparinized bovine pericardium as a novel cardiovascular bioprosthesis. Biomaterials. 2000; 21(22):2323-2330.

10. Zioupos P, Barbenel JC, Fisher JC. Mechanical and optical anisotropy of bovine pericardium. Medical \& Biological Engineering \& Computing. 1992; 30(1):76-82.

11. Du C, Cui FZ, Feng QL, Zhu XD, Groot KJ. Tissue response to nanohydroxyapatite/collagen composite implants in marrow cavity. Biomedical Materials Research. 1998; 42(4):540-548.

12. Kikuchi M, Ikoma T, Itoh S, Matsumoto HN, Koyama Y, Takakuda K, Tanaka K. Biomimetic synthesis of bone-like nanocomposites using the self-organization mechanism of hydroxyapatite and collagen. Composites Science and Technology. 2004; 64(6):819-825.

13. Ogawa CA, Plepis AMG. Estudos Preliminares de Liberação de Ciprofloxacina em Compósito Hidroxiapatita: Colágeno. Revista Brasileira de Engenharia Biomédica. 2001; 17(3):123-130.

14. Wang M, Hench L, Bonfield W. Bioglass/high density polyethylene composite for soft tissue applications: preparation and evaluation. Journal of Biomedical Materials Research. 1998; 42(4):577-586.

15. Pereira MM, Oréfice RL, Mansur H S, Lopes M T P, Turchetti-Maia M D M, Vasconcelos AC. Preparation and Biocompatibility of Poly(methyl methacrylate) Reinforced with Bioactive Particles. Materials Research. 2003; 6(3):311-315.

16. Tonhi E, Plepis AMG. Obtenção e Caracterização de Blendas ColágenoQuitosana. Química Nova. 2002; 25(6):943-948.

17. Deyl Z, Miksík I, Eckhardt A. Preparative procedures and purity assessment of collagen proteins. Journal of Chromatography B. 2003; 790(1):245-275.

18. Sato K, Tanashishiina T, Jun F, Abekawamura A, Ichinomiya M, MinegishiY, Tsukamasa Y et al. Simple and rapid chromatographic purification of type $\mathrm{V}$ collagen from a pepsin digest of porcine intestinal connective tissue, an unmanageable starting material for conventional column chromatography. Journal of Chromatography B. 2003; 790(1):277-283.

19. Eriksen HA, Sharp CA, Robins SP, Sassi ML, Risteli LJ. Differently cross-linked and uncross-linked carboxy-terminal telopeptides of type 1 collagen in human mineralised bone. Bone. 2004; 34(4):720-727.

20. Lin XY, Fan HS, Li XD, Tang M, Zhang XD. Evaluation of Bioactivity and Cytocompatibility of Nano-hydroxyapatite/Collagen Composite In vitro. Key Engineering Materials. 2005; 284-286:553-556.

21. Santos MH, Oliveira M, Souza LFP, Mansur HS, Vasconcelos WL. Synthesis Control and Characterization of Hydroxyapatite Prepared by Wet Precipitation Process. Materials Research. 2004; 7(4):625-630.

22. Santos MH, Heneine LGD, Mansur HS. Synthesis and characterization of calcium phosphate/collagen biocomposites doped with $\mathrm{Zn}^{2+}$. Materials Science and Engineering: C. in Press, (doi: 10.1016/j.msec. 2007.07.002).

23. Cullity BD. Elements of X-Ray Diffraction. 2 ed. Addison-Wesley: Reading (Massachusetts); 1978. p. 324-349.

24. Liou SC, Chen SY, Liu DM. Synthesis and characterization of needlelike apatitic nanocomposite with controlled aspect ratios. Biomaterials. 2003; 24(22):3981-3988.

25. Afshar A, Ghorbani M, Ehsani N, Saeri MR, Sorrell CC. Some important factors in the wet precipitation process of hydroxyapatite. Materials \& Design. 2003; 24(3):197-202.

26. Mavropoulos E, Rossi AM, Rocha NCC, Soares GA, Moreira JC, Moure GT. Dissolution of calcium-deficient hydroxyapatite synthesized at different conditions. Materials Characterization. 2003; 50(2-3):203-207.

27. Takeshi M, Miyamoto Y, Ishikawa K, Toh T, Yuasa T, Nagayama M, Suzuki K. Initial histological evaluation of anti-washout type fast-setting calcium phosphate cement following subcutaneous implantation. Biomaterials. 1998;19(22):2057-2061.

28. Yang X, Wang Z. Synthesis of biphasic ceramics of hydroxyapatite and -tricalcium phosphate with controlled phase content and porosity. Journal of Materials Chemistry. 1998; 8(10):2233-2237. 
29. Kikuchi M, Itoh S, Ichinose S, Shinomiya K, Tanaka J. Self-organization mechanism in a bone-like hydroxyapatite/collagen nanocomposite synthesized in vitro and its biological reaction in vivo. Biomaterials. 2001; 22(13):1705-1711.
30. Chang MC, Ko CC, Douglas WH. Preparation of hydroxyapatite-gelatin nanocomposite. Biomaterials. 2003; 24(17):2853-2862.

31. Myung CC, Tanaka J. FT-IR study for hydroxyapatite/collagen nanocomposite cross-linked by glutaraldehyde. Biomaterials. 2002; 23(24):4811-4818. 